\title{
PAY WHAT YOU WANT: WILLINGNESS TO PAY UNDER NO, PART, AND FULL INFORMATION OF COST OF PRODUCT
}

\author{
Dr. Atanu Adhikari, Indian Institute of Management Kozhikode, India
}

\begin{abstract}
In pay what you want pricing method, consumers are free to determine the price of the product (including zero) and pay accordingly. Researchers found that delegation of power to the consumer for deciding price, combined with their social status encourages them to pay a reasonable price for the product they consume. Studies suggest that consumer's willingness to pay differ in presence of information about the product than in absence.

This study investigates consumer's willingness to pay under pay what you want (PWYW) pricing strategy when they are not informed about the cost of the product, only informed about total cost of the product, and fully informed about the detail cost of the product by the seller. Experimental research is conducted in the context of food item to measure consumers' willingness to pay in PWYW pricing strategy. Two studies were conducted on food items and hot beverages. The average price paid under PWYW condition is significantly greater than zero $(\mathrm{p}<0.01)$ in all the cases studied. However, interesting finding of our research is that consumers' willingness to pay increases significantly $(\mathrm{p}<.05)$ when sellers disclose cost of the product. Unlike some of the earlier studies we found that number of units sold and total revenue under PWYW pricing are significantly higher than total number of units sold and total revenue under regular pricing (both cases $\mathrm{p}<0.01)$. It is observed that percentage increase in revenue as well as in unit sold is considerably less when consumers are exposed to social pressure (study 2) than when they are not exposed to social pressure by the seller (study 1 ). On the other hand, quite interestingly, we found that percentage of consumers' willingness to pay over the disclosed cost price by the seller is significantly higher $(\mathrm{p}<.05)$ when seller force customers to social pressure, than otherwise. This study provides a theoretical and empirical insight of how willingness to pay changes under PWYW pricing when customers are exposed to information about the cost of product by the sellers. It is also shown in this study the consumer's behaviour in pay what you want pricing when they are exposed to social pressure.
\end{abstract}

This study analyses consumers buying behaviour from different perspective and estimates the effect of pay what you want pricing on number of units sold, total revenue, total profit and percentage of increase in willingness to pay over the cost price of the items. Our experiments in line with previous researchers also show that consumers do not follow the traditional economic theory of rationality in this context pay price significantly higher than zero when there are allowed to pay nothing. The study also revealed an interesting behaviour of consumers as it found that total sales and total revenue are significantly less when consumers are exposed to social pressure than when they are not exposed to social pressure.

Reference will be available on request. 